\section{Localization of the occluded vessel in acute myocardial infarction}

\author{
Samir Rafla ${ }^{1 *}$ and Amr Kamal ${ }^{2}$ \\ ${ }^{1}$ Emeritus Professor, Cardiology Department, Alexandria University, Egypt \\ ${ }^{2}$ Lecturer of Cardiology, Alexandria University, Egypt
}

\section{Abstract}

This is a review of features in ECG to diagnose the culprit artery responsible for the infarction. Localization of the occluded vessel in acute myocardial infarction is important for many reasons: to know which artery is to dilate and stent; to assess the severity of the lesion; to compare with the echocardiographic area with hypokinesia or akinesia and to differentiate the recent from the old occluded vessel. The ST-segment changes in 12-lead ECG form the basis of diagnosis, management, and prognosis.

\section{Introduction}

Infarct related artery (culprit artery) means the coronary artery that is stenosed or occluded by thrombosis, and responsible for an acute coronary syndrome. Usually, there is one culprit artery in majority of cases [1-5].

\section{Coronary artery dominance}

The right dominant circulation is defined as RCA supplying the PDA and at least one posterolateral branch. This type is present in around $85 \%$ of patients. The non-dominant RCA is seen in $15 \%$ of patients. One half of these patients have left dominant circulation which is defined as distal LCx supplying a left PDA and left posterolateral branches. In these cases, the RCA is very small, ends before reaching the crux, and does not supply any blood to the left ventricular myocardium. The remaining patients have balanced/codominant circulation. The specificity of the ECG in acute MI is limited by large individual variations in coronary anatomy \& the presence of preexisting coronary artery disease (previous MI, collateral circulation or previous CABG). ECG is limited by its inadequate representation of the posterior, lateral, and apical walls of the left ventricle.

Major steps in the diagnosis of myocardial infarction include identification of the presence of myocardial injury and its severity; and to define the location of the lesion [6-10] (Table 1).

Localization of ischemic area in NSTE-ACS/NSTEMI is more difficult because leads with ST-segment depressions do not point exactly to the ischemic area. Thus ST-segment depressions in leads V3-V4 do not necessarily mean that

\section{More Information}

*Address for Correspondence: Samir Rafla*, MD, FACC, EFESC, FHRS, Emeritus Professor Cardiology Department, Alexandria University, Egypt, Tel: 00201001495577;

Email: smrafla@yahoo.com

Submitted: 19 November, 2019

Approved: 17 February 2020

Published: 18 February 2020

How to cite this article: Rafla S, Kamal A. Localization of the occluded vessel in acute myocardial infarction. J Cardiol Cardiovasc Med. 2020; 5: 029-033.

DOI: dx.doi.org/10.29328/journal.jccm.1001082 ORCiD: orcid.org/0000-0001-8688-6532

Copyright: (C) 2020 Rafla S, et al. This is an open access article distributed under the Creative Commons Attribution License, which permits unrestricted use, distribution, and reproduction in any medium, provided the original work is properly cited.

Keywords: Infarct related artery; Culprit vessel; Acute coronary syndrome; Coronary angiography; Magnetic resonance imaging; Myocardial infarction; Electrocardiogram; ST-elevation

Abbreviations: IRA: Infarct Related Artery; STD: ST segment Depression: STE: ST segment Elevation

Check for updates

OPEN ACCESS

the ischemia is located in the anterior wall. Therefore, it is commonly stated that ST-segment depressions (as well as $\mathrm{T}$-wave inversions) cannot be used to localize the ischemic area. In exception to this rule, Wellen's syndrome and de Winter's sign, both of which are caused by proximal occlusions in the LAD and thus cause anterior wall ischemia/infarction [11-15].

Wellens syndrome refers to specific ECG abnormalities in the precordial T-wave segment, which are associated with

Table 1: Localization of ischemic area in ST segment elevation myocardial infarction (STEMI or STE-ACS).

\begin{tabular}{|c|c|c|}
\hline $\begin{array}{c}\text { Leads with ST segment } \\
\text { elevation }\end{array}$ & $\begin{array}{c}\text { Affected myocardial } \\
\text { area }\end{array}$ & $\begin{array}{c}\text { Occluded coronary artery } \\
\text { (Culprit) }\end{array}$ \\
\hline V1-V2 & Septal & Proximal LAD \\
\hline V3, V4 & Anterior & LAD \\
\hline V5, V6 & Apical & Distal LAD \\
\hline I, aVL & Lateral & LCx \\
\hline II, aVL, III & Inferior & $90 \%$ RCA. 10\% LCx \\
\hline $\begin{array}{c}\text { V7, V8, V9 (reciprocal ST } \\
\text { depressions are frequently } \\
\text { evident in V1 to V3) }\end{array}$ & $\begin{array}{c}\text { Posterolateral } \\
\text { (also referred to as } \\
\text { inferobasal or posterior) }\end{array}$ & RCA or LCx \\
\hline
\end{tabular}




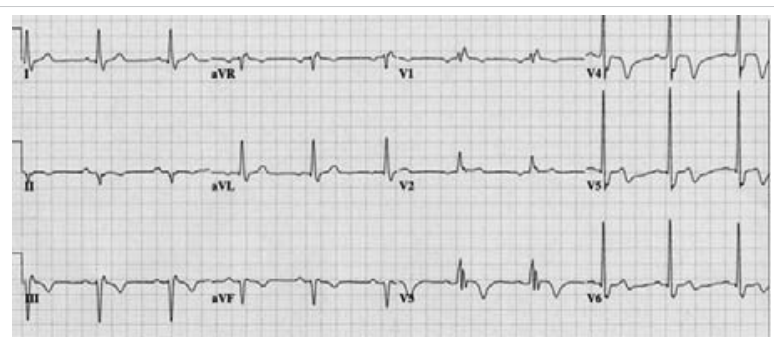

Figure 1: Wellens syndrome.

Wellens syndrome refers to specific ECG abnormalities in the precordial T-wave segment, which are associated with critical stenosis of the proximal left anterior descending (LAD) coronary artery.

critical stenosis of the proximal left anterior descending (LAD) coronary artery [15]. Syndrome criteria include the following:

Characteristic T-wave changes

History of anginal chest pain

Normal or minimally elevated cardiac enzyme levels

ECG without Q waves, without significant ST-segment elevation, and with normal precordial R-wave progression.

Recognition of this ECG abnormality is of important because this syndrome represents a pre-infarction stage of coronary artery disease (CAD) that often progresses to a severe anterior wall MI.

Identifying myocardial injury and the involved cardiac areas:

\section{Anterior V1-4}

Apical V5-6

Lateral I, AVL

Inferior II, III, aVF

- Posterior ischemia is shown by ST depression in leads V1-3, but posterior injury may best be diagnosed by recording posterior leads V7, V8 and V9.

Right ventricle: The most sensitive sign of RV injury is ST segment elevation $>1 \mathrm{~mm}$ in lead V4R. A specific sign of RV injury and/or infarction is ST elevation in V1, with concomitant ST segment depression in V2 associated with ST elevation in the inferior leads.

- Primary anterior area:

ST elevation in V1-4

areas contiguous are Lateral (L1, aVL), Apical(V5,6)

- Primary inferior area:

ST segment elevation in two contiguous leads ((II. III. aVF)

areas contiguous:
V5,6---------- $\rightarrow$ apical

V7-9, or V1-3, ------- $\rightarrow$ posterior

V4R

- These contiguous leads suggest more myocardium at risk.

- Primary anterior injury: acute occlusion of the LAD coronary artery, producing changes in the anterior leads (V1- 4).

- Earliest findings of occlusion:

- "Hyperacute" changes: ST elevation (injury) with loss of normal ST segment concavity, commonly with tall peaked $\mathrm{T}$ waves.

- Acute injury: ST elevation (Figure 2).

Why left anterior fascicle is usually blocked with the RBB? Because the left posterior fascicle receives dual blood supply but both right bundle and left anterior fascicle receive same blood supply.

Proximal occlusion in LAD: Results in massive infarction, the more proximal the occlusion, the more the number of leads that display ST-segment elevation. Occlusion proximal to the first septal and diagonal branch causes ST-segment elevations in V1-V4, aVL and I, as well as reciprocal STsegment depressions in II, III, aVF, aVR. New right bundle branch block is common.

Distal occlusion of LAD: Occlusion distal to the first diagonal and first septal will spare the basal parts of the anterior wall. ST-segment elevations are seen in V2-V6. There are no ST-segment elevations in V1, I or aVL. And no reciprocal ST-segment depressions in II, III, aVF and aVR.

Occlusion in a long LAD: If the LAD is very long and supplies a significant portion of the inferior wall, occlusion may cause inferior ST-elevations. Thus, a very distal occlusion in the LAD may be deceptive.

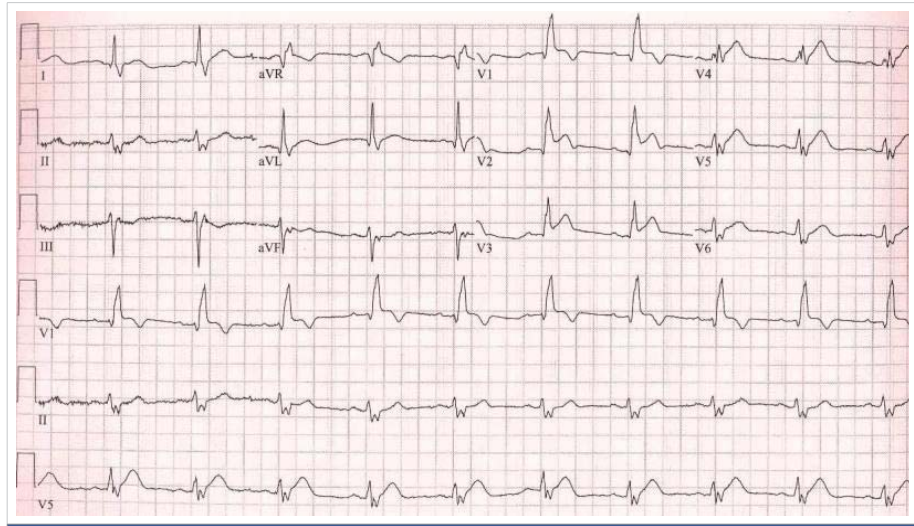

Figure 2: Right bundle branch block with left axis (left anterior hemiblock) bifascicular block. There is anteroseptal infarction. 


\section{Primary inferior process}

Usually acute occlusion of the right coronary artery, producing changes in the inferior leads (II, aVF \& III).

- Earliest findings:

Acute injury: (ST segment elevation) The J point may "climb up the back" of the R wave (a), or the ST segment may rise up into the $\mathrm{T}$ wave (b).

Evolutionary changes:

E ST segment elevation decreases and pathologic $\mathrm{Q}$ waves develop.

$\mathrm{T}$ wave inversion may occur in the $1^{\text {st }} 12$ hours of an inferior MI, in contrast to that in anterior MI.

\section{Inferior myocardial infarction}

The culprit vessel in inferior MI: RCA (in 80\%) or CX.

Greater ST-segment elevation in lead III than in lead II \& ST-segment depression of more than $1 \mathrm{~mm}$ in leads I and aVL suggest involvement of the RCA rather than the CX.

ST-segment depression in leads V1 and V2 suggest concomitant infarction of the posterior wall of the left ventricle[(16-20].

\section{Right ventricular myocardial infarction}

ST-segment elevation of $>1 \mathrm{~mm}$ in lead V4R with an upright $\mathrm{T}$ wave in that lead: This sign is rarely present more than 12 hours after the infarction (Figure 3).

ST-segment elevation in lead V1 in association with ST-segment elevation in leads II, III, and aVF (with greater elevation in III > II) is highly correlated with the presence of right ventricular infarction (Figure 4).

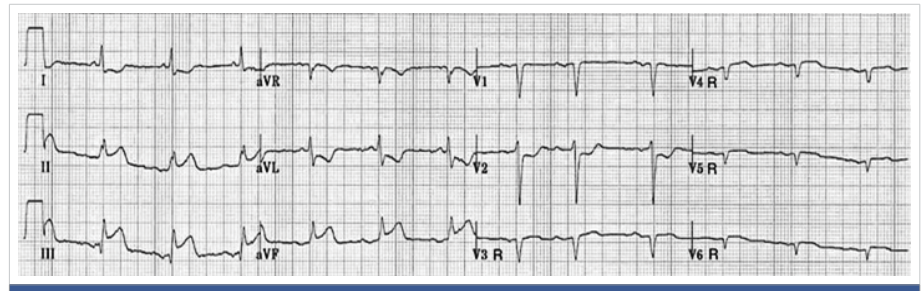

Figure 3: Right Ventricular Myocardial Infarction.

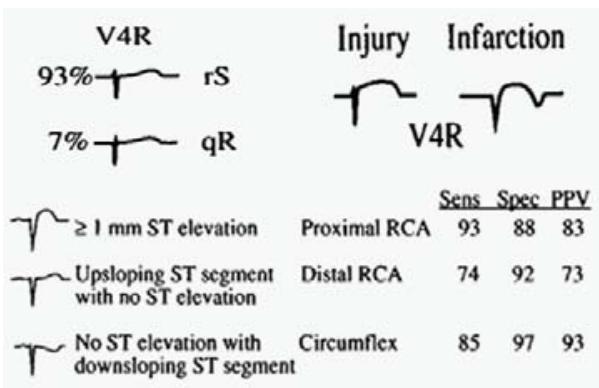

Figure 4: Identification of the culprit artery in patients with inferior injury based upon the QRS-ST-T morphology in lead V4R.

\section{Posterior injury or infarction}

Acute occlusion of the CX producing changes in the posterior leads (V7, V8, V9), or reciprocal ST segment depression in leads V1-3.

Identifying the location of the lesion within the artery:

Proximal LAD occlusion

1-ST elevation $>1 \mathrm{~mm}$ in either lead I, aVL, or both

2-New right bundle branch block

3-New left anterior fascicular block

4-New first-degree A-V block

Identifying the location of the lesion within the artery:

ST-segment elevation in leads V1, V2, and V3 without significant inferior ST-segment depression suggests occlusion of the LAD after the origin of the first diagonal branch.

ST-segment elevation in leads V1, V2, and V3 with elevation in the inferior leads: Occlusion of the LAD distal to the origin of the first diagonal branch, in a vessel that wraps around to supply the inferoapical region of the left ventricle (Figure 5).

\section{Lead aVR}

Lead aVR has a frontal plane vector of $-150^{\circ}$, which faces the inside of heart from the right shoulder and is oriented to look at the outflow area of right ventricle and basal part of interventricular septum. Lead aVR ST segment elevation has been reported in cases of acute LMCA occlusion.

New RBBB with a $\mathrm{Q}$ wave preceding the $\mathrm{R}$ wave in lead V1 is a specific but insensitive marker of proximal occlusion of the LAD in association with anteroseptal myocardial infarction.

Defining the age of an infarction: Acute infarction manifests ST segment elevation in a lead with a pathologic $Q$ wave. Old or age indeterminate infarction manifests a pathologic $Q$ wave, with or without slight ST segment elevation or T wave abnormalities [21-27].

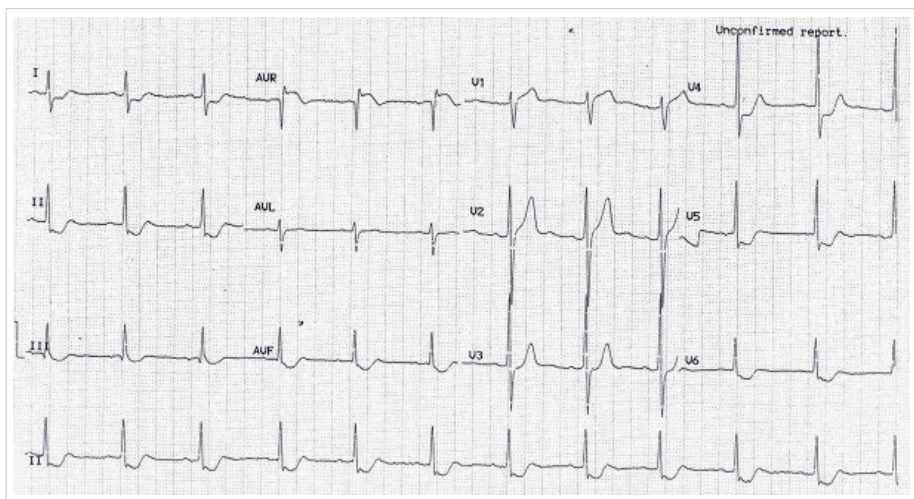

Figure 5: ECG showing ST elevation in aVR > V1 with upright T wave in lead aVL. Coronary angio revealed isolated proximal LCx occlusion. 


\section{ST segment scoring}

Anterior wall myocardial infarction: Total amount (in millimeters) of ST elevation in the precordial leads (V1-V6). A total of $=>12 \mathrm{~mm}$ is a high ST segment score and indicates extensive anterior wall infarction; $<12 \mathrm{~mm}$ a low ST segment score.

Inferior wall myocardial infarction: Total amount (in millimeters) of ST segment elevation in the inferior leads (II, III, and aVF). A total of $=>7 \mathrm{~mm}$ is a high ST segment score and indicates extensive inferior wall infarction $<7 \mathrm{~mm}$ a low ST segment score.

Persistent ST segment elevation after acute MI: Persistent ST segment elevation $>1 \mathrm{~mm}$ after a myocardial infarction was a sign of dyskinetic wall motion in the area of infarct. One-half of these patients had echocardiographically defined aneurysm.

Electrocardiographic predictors of reperfusion: Resolution of ST-segment elevation: The degree of resolution has proved to be a powerful indicator of short-term (30 day) and long-term (1-year) prognosis.

The absence of ST-segment resolution during the first 90 minutes after the administration of fibrinolytic medications should prompt consideration of rescue angioplasty.

A reduction in ST-segment elevation by more than 70 percent in the leads with maximal elevation is associated with the most favorable outcomes

ECG Predictors of Reperfusion: T-wave inversion that occurs during the first few hours of reperfusion therapy are a highly specific sign of reperfusion T-wave inversion $>4$ hours after the start of reperfusion therapy is consistent with the normal electrocardiographic evolution of myocardial infarction and does not indicate that reperfusion has occurred.

An accelerated idioventricular rhythm, (HR 60 to 120 beats per minute is a specific marker of reperfusion. Isolated ventricular premature depolarizations may also be seen with reperfusion. Polymorphic VT, VF can be seen with reperfusion but are rare and should raise the probability of persistent arterial occlusion.

\section{ECG in AMI with LBBB}

The diagnosis of MI in the presence of LBBB is not easy $50 \%-70 \%$ of patients with LBBB and suspected MI are not actually having an infarct.

Scoring system for the ECG diagnosis of acute MI with LBBB [27].

* ST elevation $=>1 \mathrm{~mm}$ concordant with the QRS complex $=5$ points.

* $\quad$ ST depression $=>1 \mathrm{~mm}$ in lead $\mathrm{V} 1, \mathrm{~V} 2$ or $\mathrm{V} 3=3$ points.
* ST elevation $=>5 \mathrm{~mm}$ discordant with the QRS complex $=2$ points.

A score of $=>3$ points is consistent with a diagnosis of MI.

Criteria for diagnosing prior infarction in the setting of LBBB:

- Notching 0.04 seconds in duration in the ascending limb of the S wave in leads V3, V4, or V5(Cabrera's sign)

- Notching of the upstroke of the R wave in leads I, L, or V6 (Chapman's sign)

- Presence of QR complexes in leads I and V5 or V6; or in II, III, and aVF

- Notching in the first 0.04 seconds of the QRS in leads II, III, and aVF

\section{Limitations of electrocardiogram}

Assessment of the site of occlusion of a coronary vessel is most reliable in case of a first episode of MI. This is impaired by multivessel disease, an old MI, collateral circulation and when ventricular activation is altered as in pre-existent left bundle branch block, preexcitation and paced rhythm.

\section{Conclusion}

ECG information can help to expect culprit artery involved before angiography.

\section{References}

1. Amsterdam EA, Wenger NK, Brindis RG, Casey DE, Ganiats TG, et al. $2014 \mathrm{AHA} / \mathrm{ACC}$ guideline for the management of patients with nonST- elevation acute coronary syndromes: executive summary: a report of the American College of Cardiology/American Heart Association Task Force on Practice Guidelines. Circulation. 2014; 130: 2354-2394. PubMed: https://www.ncbi.nlm.nih.gov/pubmed/25249586

2. Kerensky RA, Wade M, Deedwania $P$, Boden WE, Pepine CJ, et al. Revisiting the culprit lesion in non-Q-wave myocardial infarction. Results from the VANQWISH trial angiographic core laboratory. J Am Coll Cardiol. 2002; 39: 1456-1463.

PubMed: https://www.ncbi.nlm.nih.gov/pubmed/11985907

3. Kim HW, Farzaneh-Far A, Kim RJ. Cardiovascular magnetic resonance in patients with myocardial infarction: current and emerging applications. J Am Coll Cardiol. 2009; 55: 1-16.

PubMed: https://www.ncbi.nlm.nih.gov/pubmed/20117357

4. Brener SJ, Milford-Beland S, Roe MT, Bhatt DL, Weintraub WS, et al. Culpritonly or multivessel revascularization in patients with acute coronary syndromes: an American College of Cardiology National Cardiovascular Database Registry report. Am Heart J. 2008; 155: 140-146.

PubMed: https://www.ncbi.nlm.nih.gov/pubmed/18082505

5. Budge LP, Salerno M. The role of cardiac magnetic resonance in the evaluation of patients presenting with suspected or confirmed acute coronary syndrome. Cardiol Res Pract. 2011; 2011: 605785. PubMed: https://www.ncbi.nlm.nih.gov/pubmed/22028981

6. Amier RP, Smulders MW, van der Flier WM, Bekkers SCAM, Zweerink A, et al. Long-term prognostic implications of previous silent myocardial infarction in patients presenting with acute myocardial infarction. JACC Cardiovasc Imaging. 2018; 11: 1773-1781.

PubMed: https://www.ncbi.nlm.nih.gov/pubmed/29680352 
7. Midgette AS, Griffith JL, Califf RM, Laks MM, Dietz SB, et al. Prediction of the Infarct-Related Artery in Acute Myocardial Infarction by a Scoring System Using Summary ST-Segment and T-Wave Changes. Am J Cardiol. 1996; 78: 389-395.

PubMed: https://www.ncbi.nlm.nih.gov/pubmed/8752181

8. Thejanandan Reddy CS, Rajasekhar D, Vanajakshamma V Electrocardiographic localization of infarct related coronary artery in acute ST elevation myocardial infarction. J Clin Sci Res 2013; 2: 151-60.

9. Baltazar RF. Acute Coronary Syndrome: ST Elevation Myocardial Infarction. In: BaltazarRF, editor. Basic and bedside electrocardiography. $1^{\text {st }}$ edition. Baltimore: Lippincott Williams and Wilkins. 2009; 337-339.

10. Popma JJ. Coronary arteriography. In: Bonow OR, Mann DL, Zipes DP Libby P, Braunwald E, editors. Braunwald's heart disease. A textbook of cardiovascular medicine. $9^{\text {th }}$ edition. St. Louis: Elsevier Saunders. 2012; 428-431.

11. Wagner GS, Macfarlane P, Wellens $H$, Josephson M, Gorgels $A$, et al. AHA/ACCF/HRS recommendations for the standardization and interpretation of the electrocardiogram: part $\mathrm{Vl}$ : acute ischemia/ infarction: a scientific statement from the American Heart Association Electrocardiography and Arrhythmias Committee, Council on Clinical Cardiology; the American College of Cardiology Foundation; and the Heart Rhythm Society. Endorsed by the International Society for Computerized Electrocardiology. J Am Coll Cardiol 2009; 53: 1003-1011. PubMed: https://www.ncbi.nlm.nih.gov/pubmed/19281933

12. Fiol M, Carillo A, Cygankiewicz I, Velasco J, Riera M, et al. A New Electrocardiographic Algorithm to Locate the Occlusion in Left Anterior Descending Coronary Artery. Clin Cardiol. 2009; 32: E1-E6.

PubMed: https://www.ncbi.nlm.nih.gov/pmc/articles/PMC6652907

13. Zimetbaum P, Krishnan S, Gold A, Carrozza JP II, Josephson M Usefulness of ST segment elevation in lead III exceeding that of lead II for identifying the location of the totally occluded coronary artery in inferior wall myocardial infarction. Am J Cardiol 1998; 81: 918-919. PubMed: https://www.ncbi.nlm.nih.gov/pubmed/9555783

14. Zimetbaum PJ, Josephson ME. Use of the electrocardiogram in acute myocardial infarction. N Engl J Med. 2003; 348: 933-940.

PubMed: https://www.ncbi.nlm.nih.gov/pubmed/12621138

15. Wellens HJJ. Determining the size of the area at risk, the severity of ischemia, and identifying the site of occlusion in the culprit coronary artery. In: Wellens HJJ, Gorgels APM, Doevendans PA, editors. The ECG in acute myocardial infarction and unstable angina: diagnosis and risk stratification. 2nd edition. Dordrecht: Kluwer Academic Publishers. 2003; $13-43$

16. Herz I, Assali AR, Adler Y, Solodky A, Sclarovsky S. New electrocardiographic criteria for predicting either the right or left circumflex artery as the culprit coronary artery in inferior wall acute myocardial infarction. Am J Cardiol. 1997; 80: 1343-1345.

PubMed: https://www.ncbi.nlm.nih.gov/pubmed/9388111

17. Bairey CN, Shah K, Lew AS, Hulse S. Electrocardiographic differentiation of occlusion of the left circumflex versus the right coronary artery as a cause of inferior acute myocardial infarction. Am J Cardiol. 1987; 60: 456-459

PubMed: https://www.ncbi.nlm.nih.gov/pubmed/3630927

18. Bayes de Luna A, Goldwasser D, Fiol M, Bayes Genis A. Surface electrocardiography. In: Fuster V, Walsh RA, Harrington RA' editors. Hurst's the heart. $13^{\text {th }}$ edition. New York: McGraw Hill. 2011; 350-358.

19. Hasdai D, Birnbaum Y, Herz I, Sclarovsky S, Mazur A, et al. ST segment depression in lateral limb leads in inferior wall acute myocardial infarction: implications regarding the culprit artery and the site of obstruction. Eur Heart J. 1995; 16: 1549-1553. PubMed: https://www.ncbi.nlm.nih.gov/pubmed/8881846

20. Verouden NJ, Barwari K, Koch KT, Henriques JP, Baan J, et al Distinguishing the right coronary artery from the left circumflex coronary artery as the infarct-related artery in patients undergoing primary percutaneous coronary intervention for acute inferior myocardial infarction. Europace. 2009; 11: 1517-1521.

PubMed: https://www.ncbi.nlm.nih.gov/pubmed/19706635

21. Rott D, Nowatzky J, Teddy Weiss A, Chajek-Shaul T, Leibowitz D. ST Deviation Pattern and Infarct-related Artery in Acute Myocardial Infarction. Clin Cardiol. 2009; 32: E29-E32.

PubMed: https://www.ncbi.nlm.nih.gov/pubmed/19816991

22. Gorgels AP, Engelen DJ, Wellens HJ. Lead aVR, a mostly ignored but very valuable lead in clinical electrocardiography. J Am Coll Cardiol. 2001; 38: 1355-1356.

PubMed: https://www.ncbi.nlm.nih.gov/pubmed/11691507

23. Yamaji H, Iwasaki K, Kusachi S, Murakami T, Hirami R, et al. Prediction of acute left main coronary artery obstruction by 12-lead ECG. ST segment elevation in lead aVR with less ST segment elevation in lead V1. J Am Coll Cardiol. 2001; 38: 1348-1354.

PubMed: https://www.ncbi.nlm.nih.gov/pubmed/11691506

24. Thrudeep S, Geofi G, Rupesh G, Abdulkhadar S. Dilemma of localization of culprit vessel by electrocardiography in acute myocardial infarction. Indian Heart J. 2016; 68(Suppl 2): S15-S17.

PubMed: https://www.ncbi.nlm.nih.gov/pubmed/27751270

25. Heslop JJ, Narala K, Banga S, Mungee S. Anteroseptal ST elevation myocardial infarction and non-dominant right coronary artery lesion involving acute marginal branch: a dilemma in decision making. JACC. 2015.

26. Jothieswaran A, Body R. BET 2: Diagnosing acute myocardial infarction in the presence of ventricular pacing: can Sgarbossa criteria help? Emerg Med J. 2016; 33:

PubMed: https://www.ncbi.nlm.nih.gov/pubmed/27539980

27. Sgarbossa EB, Pinski SL, Barbagelata A, Underwood DA, Gates KB, et al. Electrocardiographic Diagnosis of Evolving Acute Myocardial Infarction in the Presence of Left Bundle-Branch Block. N Engl J Med. 1996; 334: 481-487.

PubMed: https://www.ncbi.nlm.nih.gov/pubmed/8559200 